\title{
Use of the excavation compliance indicator at the Oyu Tolgoi copper-gold mine, Mongolia
}

\author{
A Juldyz Oyu Tolgoi LLC, Mongolia
}

\begin{abstract}
Systematic assessment of 'as-built' open pit mine slopes is required to verify that slope design criteria are appropriate for the ground conditions and that slope designs are being correctly implemented by mine operations. It is imperative that design bench geometry and inter-ramp slope angles are delivered (in order to meet scheduled production targets), slope design acceptance criteria are achieved, and that geotechnical design risks are appropriately managed, so that the design intent is met.

The excavation compliance indicator (ECI) as developed by Seery and Lapwood (2007) and presents a methodology for quantifying compliance to design via measurement of the 'as-built' individual geometrical elements that comprise the bench geometry; i.e. bench face angle (BFA), crest position, toe position and catch bench width (CBW). Measurements of these elements are combined and weighted in order to deliver an overall slope design conformance metric (i.e. the $\mathrm{ECl}$ score). The technique enables valuable insights into the contributing factors that adversely affect design implementation conformance, thereby enabling operational practices to be modified in order to deliver improved design achievement.

This paper outlines how the Oyu Tolgoi (OT) open pit geotechnical team implements ECI and how it is integrated into their design reconciliation workflow. This paper also provides some recommendations for improving the $\mathrm{ECl}$ process.
\end{abstract}

Keywords: pit design, design achievement, excavation compliance indicator

\section{Introduction}

Systematic measurement of slope design conformance (i.e. comparison of 'as-built' to design slopes) forms a fundamental aspect of the safe management of open pit mine slopes. To this end, the Rio Tinto D3 Management Standard, which is the framework developed by Rio Tinto for the management of slope geotechnical hazards, mandates that a slope conformance measurement process be developed for engineered slopes (in order to reconcile against design). Design conformance is required to verify that slope design criteria are appropriate for the ground conditions and that slope designs are being correctly implemented by mine operations. It is imperative that design bench geometry and inter-ramp slope angles are delivered (in order to meet scheduled production targets), slope design acceptance criteria are achieved, and that geotechnical design hazards are appropriately managed, so that the design intent is met.

The excavation compliance indicator (ECl), as developed by Seery and Lapwood (2007), presents a methodology for quantifying implementation of the pit wall design. The technique measures compliance to design via measurement of the 'as-built' individual geometrical elements that comprise the bench geometry; i.e. bench face angle (BFA), crest position, toe position and catch bench width (CBW). Measurements of these elements are combined and weighted in order to deliver an overall slope design conformance metric (i.e. the $\mathrm{ECl}$ score). The technique quantifies the implementation of the design, and highlights areas where further investigation is required to determine the contributing factors that adversely affect design achievement (i.e. blasthole deviation, blast damage, poor rock mass quality, major structural influences, operational practices, etc.), thereby enabling operational practices to be modified in order to deliver improved design achievement.

The ECI method can be applicable in rock mass or structurally controlled bench-scale instability or back-break, i.e. irrespective of the cause, the method can be used to quantify deviation from design. The $\mathrm{ECl}$ tool 
therefore provides quantifiable evidence to determine whether the design BFA is appropriate for the prevailing ground conditions. This has important implications since increasing or decreasing BFA and CBW in a kinematically designed slope may impact mine operations by increasing the risk of rockfalls or bench-scale failures, although increasing the potential for instability in the bench face is countered by an increase in catch retention for the potential spill volume (Seery \& Lapwood 2007). At the Oyu Tolgoi (OT) mine, documented bench-scale failures are typically controlled by structure rather than rock mass failure. Moreover, the majority of recorded back-breaks (i.e. surveyed during limits blast inspections) on catch benches are typically structurally controlled. Oyu Tolgoi (OT) makes extensive use of photogrammetry and structural interpretation to assist with identifying the nature and causes of crest back-break.

Therefore, the purpose of this study is to:

- Outline how OT implements the ECI procedure.

- Propose further refinements to the $\mathrm{ECl}$ method so as to:

- Improve current $\mathrm{ECl}$ reconciliation practices (i.e. by adapting to OT site conditions).

- Better quantify design implementation for application to future pit design (i.e. by providing a rational basis for defining practically achievable BFAs and CBWs based on engineered slope design acceptance criteria, prevailing ground conditions, and operational capabilities).

\section{Methodology}

\subsection{Excavation compliance indicator calculation method}

Since open pit mining commenced in 2012, OT has quantified implementation of the pit design using the bench design achievement method described in Williams et al. (2009) for the Chuquicamata mine without any modifications (Table 1). Since 2012, OT has completed mining in Phases 1 to 3 (via a series of pushbacks) and mining is currently progressing concurrently in Phases $4 \mathrm{a}$ and $4 \mathrm{~b}$.

The method, as described in Williams et al. (2009), involves a matrix, which includes:

- Design achievement (Df) for bench configuration (the principal focus of this paper).

- Face condition $(\mathrm{Fc})$ (after excavation and wall scaling).

Table 1 Design achievement (Df) calculation guide (Williams et al. 2009)

\begin{tabular}{llll}
\hline \multicolumn{3}{c}{ Design achievement (Df) } & \\
Component (weighting) & Assigned values & \multicolumn{1}{c}{ Comments } \\
\hline BFA (50\%) & $\geq$ Design & 50 & Achieved overall \\
& Design $-3^{\circ}$ & 25 & BFA relative to \\
& Design- $5^{\circ}$ & 10 & design \\
& Design- $10^{\circ}$ & 0 & \\
& $\geq$ Design & 40 & Achieved average \\
Bench width (40\%) & Design $-1 \mathrm{~m}$ & 35 & bench width \\
& Design $-2 \mathrm{~m}$ & 25 & relative to design \\
& Design $-3 \mathrm{~m}$ & 15 & \\
& Design $-5 \mathrm{~m}$ & 0 & \\
& On design & 10 & Is design toe being \\
& Design $-1 \mathrm{~m}$ & 8 & achieved? \\
Toe (10\%) & Design $-2 \mathrm{~m}$ & 5 & \\
& Design $-3 \mathrm{~m}$ & 0 & \\
& & & \\
& &
\end{tabular}




\subsection{Issues with the design achievement assessment method}

OT has experienced some difficulties quantifying achieved final wall geometry using the method described in Williams et al. (2009). The following observations are noted with the methodology as it is currently conceived (see also Figures $1(\mathrm{a})$ and $1(\mathrm{~b})$ ):

- Over-steepening of the bench face is treated as achievement of the design (i.e. if design BFA is $75^{\circ}$ and the actual BFA $\geq 75^{\circ}$, then a top score of 50 is assigned).

- The use of absolute variation values $\left(-3^{\circ},-5^{\circ}\right.$, etc.) does not consider the bench height. For example, a $3^{\circ}$ variation from design is much more significant on a $24 \mathrm{~m}$ high face than on a $10 \mathrm{~m}$ high one.

- The same thing applies to CBW where use of absolute variation ( $-1 \mathrm{~m},-3 \mathrm{~m}$, etc.) doesn't take account of catch bench width. For example, loss of $2 \mathrm{~m}$ catch capacity on an $8 \mathrm{~m}$ ( $25 \%$ loss) wide bench is more significant than on a $20 \mathrm{~m}$ (10\% loss) wide catch bench.

- Actual toe position behind the design is treated as achievement of the design. While no remnant unbroken toe left after a blast may be a drill and blast objective, no damage at the base of the bench face is a geotechnical objective.

- BFA and CBW are not independent, although the scoring method in the assessment treats them as though they are.

- With the OT slope geometry, BFA is off-design by approximately $7^{\circ}$ when the crest and toe are both on design (i.e. within the $1 \mathrm{~m}$ tolerance limit). See Figure 1(a).

- BFA is off-design by approximately $4^{\circ}$ when the crest is on design and the toe is on design but at the $1 \mathrm{~m}$ tolerance limit (Figure 1(b)).

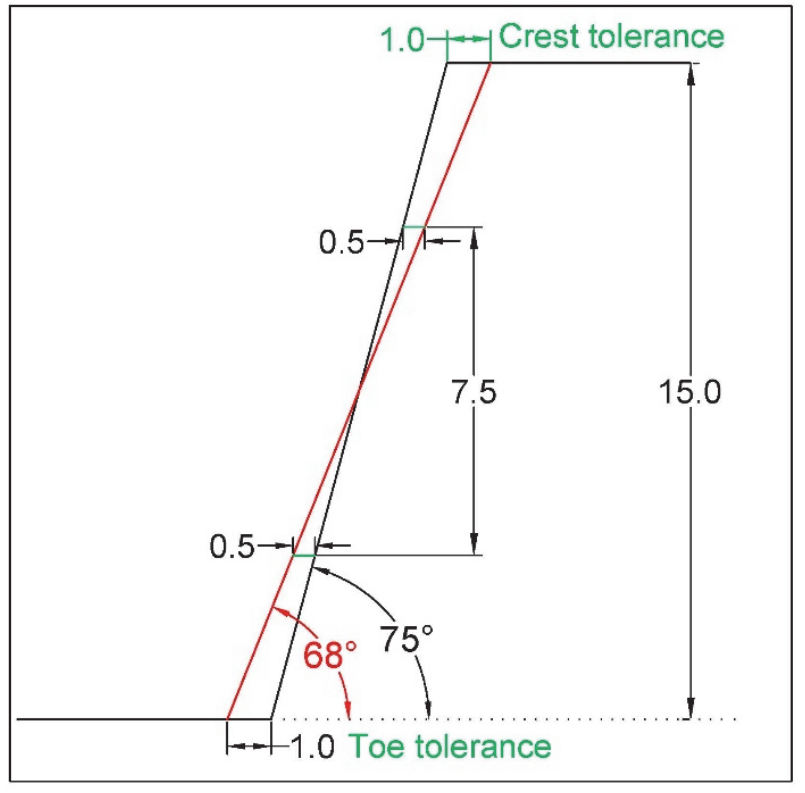

(a)

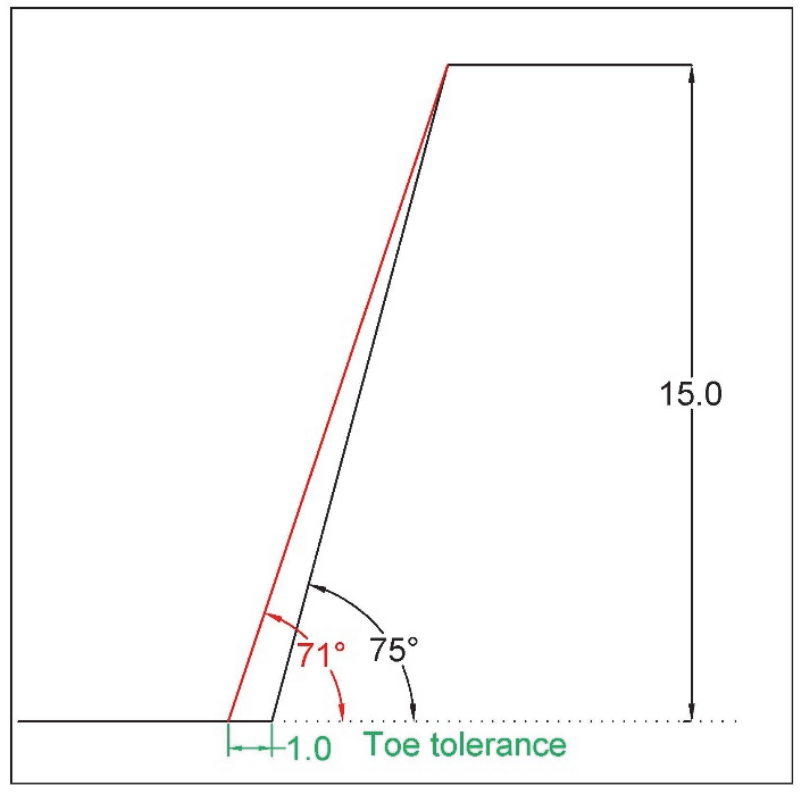

(b)

Figure 1 Schematic sections showing geometrical inconsistencies. (a) Toe and crest on design within $1 \mathrm{~m}$ tolerance; (b) Crest on design within $1 \mathrm{~m}$ tolerance 


\subsection{Proposed excavation compliance indicator calculation method}

\subsubsection{Proposed modifications to excavation compliance indicator methodology}

Every deposit has its own specific litho-structural characteristics and mining practices that may directly or indirectly affect design achievement and ECI score. In this regard, Williams et al. (2009) noted that "This system is general and should be modified for specific site conditions...", and "...the system should be adapted to their conditions". The OT open pit geotechnical team has investigated several options for customising and developing the $\mathrm{ECl}$ methodology, such that it quantifies slope design conformance specific for the circumstances at the OT open pit phases and seeks to address the issues outlined in Section 2.1.

There are four geometrical slope components that can be used for quantifying compliance of the 'as-built' geometry to the design geometry (refer to Table 2 which lists the various geometrical elements comprising the bench geometry). Of these elements, the follow points are noted:

- Delivering BFA on design is primarily a pit efficiency and economic imperative (i.e. deliver planned value).

- Delivering CBW on design is a safety imperative (i.e. management of rockfall risk).

- Crest position and toe position are critical elements of the bench configuration since both BFA and CBW are fully dependent on these components.

Table 2 Bench geometry components

\begin{tabular}{llll}
\hline Geometrical element & Abbreviation & Geometry type & Calculation/construction type \\
\hline Bench face angle & BFA & Line & Line angle \\
Catch bench width & CBW & Line & Line length \\
Toe & TOE & point & Point position \\
Crest & CREST & point & Point position \\
\hline
\end{tabular}

In terms of geometry type, both BFA and CBW can be considered as construction lines that may lie ahead (i.e. in front) of the design, or behind the design (Figure 2(a)). In such cases, BFA and CBW may be the same angle or length as the design, but this does not imply bench configuration is actually on design (i.e. the variation in position between actual and design might misrepresent design conformance). In such circumstances, crest position becomes a critical element (toe is projected using the achieved BFA angle) since crest and toe are point formats and it is more effective to calculate variability of actual crest or toe position relative to design crest or toe. In this case, there are two separate toes in question (refer to Figure 2(b) for explanation); the upper toe is used to quantify CBW on the overlying bench and the lower toe is a component of the BFA on the current mining bench.

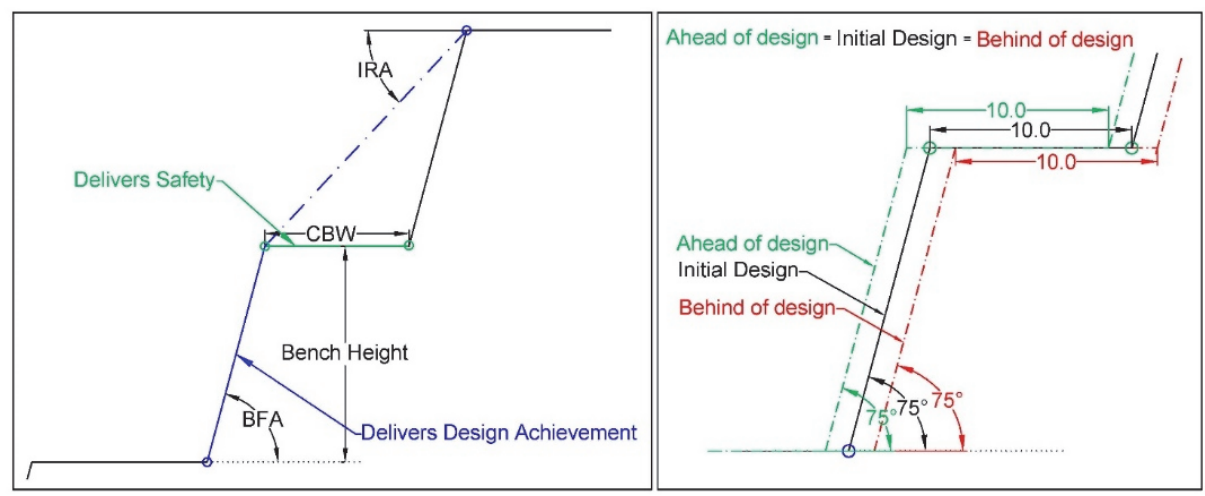

Figure 2 Geometrical elements and achieved bench profile variability. (a) Geometrical elements; (b) Bench profile variability 
Given the above, in order to maximise effective CBW (i.e. deliver both safety and pit value), crest loss (back-break) and hard toe (under-break) are the focus for design achievement/implementation. At OT, there is often a small muck pile at the bench toe due to the inability of the large bucket size of the dedicated scaling excavator to completely clean out the toe (and possibly the occurrence of some hard toe beneath this muck pile due to ineffective blasting).

For the purposes of ECl calculation, based on the typical OT survey scan data and half-barrel visibility in the lower section of face, the muck pile height at the toe generally lies between 1.5-3.0 m above bench floor elevation. The survey scan therefore provides a clear lower toe point on the bench face (above the muck pile) for extending the face angle to a projected toe position at the required bench elevation. This obviates the need for manually picking/interpreting a toe line based on the lower part of the survey profile, which is generally obscured by, loose spoil. Figure 3 shows a typical cross-section that illustrates the OT trim shot pattern design, scaled bench face profile and various geometric elements.

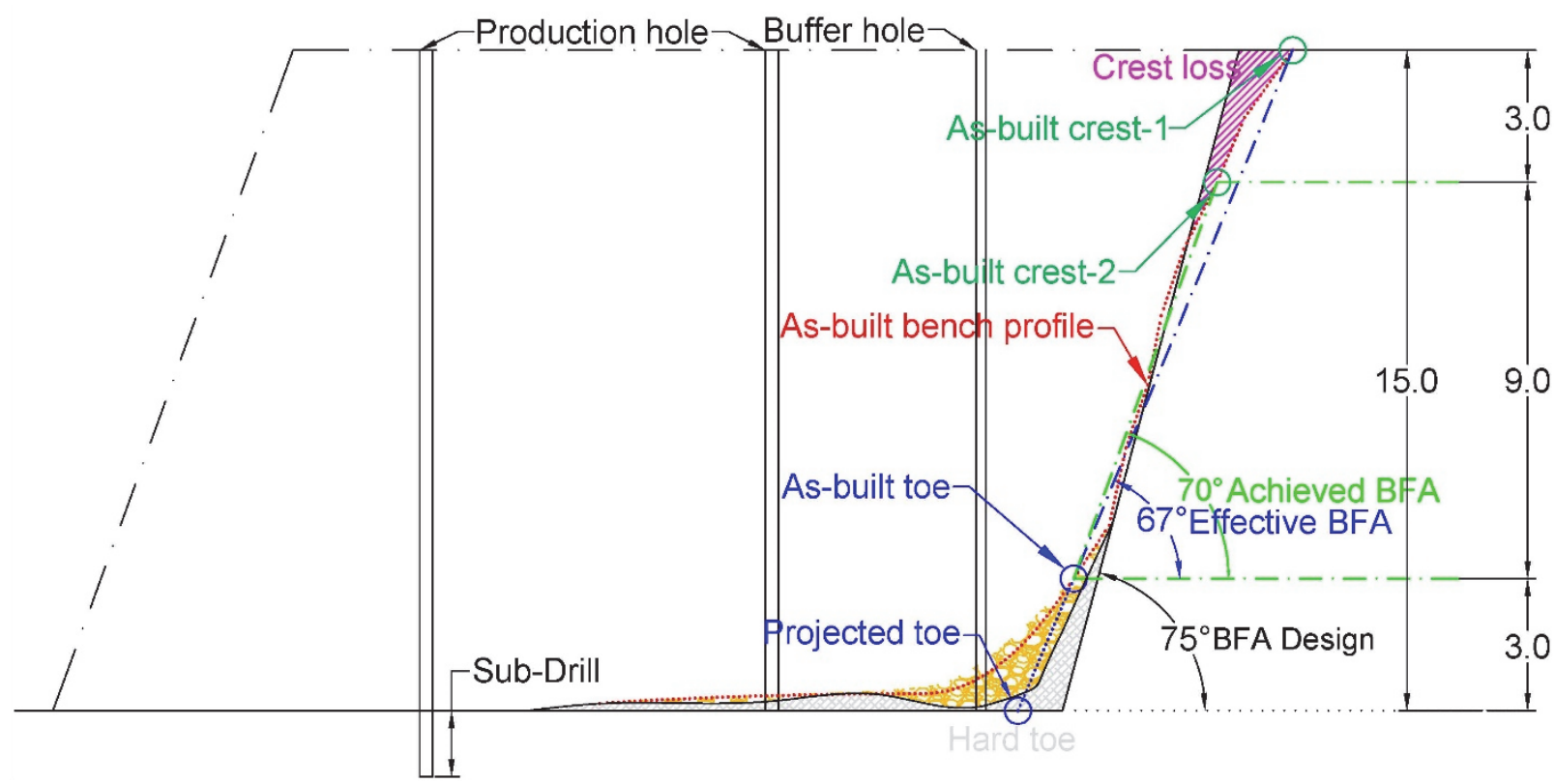

Figure 3 Typical cross-section showing geometrical elements

In terms of toe projection (to derive BFA), OT has adopted the following two methodologies:

- Measurement from the crest loss (i.e. defined by back-break/over-dig from the design crest position) to the projected toe to define an effective BFA.

- Assuming an optimised crest loss using an 'as-built crest-2' positioned $3 \mathrm{~m}$ below the catch bench elevation to define an achieved BFA (refer to Figure 3). Various combinations have been assessed to estimate the typical crest loss height between $1-5 \mathrm{~m}$. The $3 \mathrm{~m}$ position below catch bench elevation has been chosen to best reflect the achieved BFA represented by half-barrels visible on bench faces at OT (refer to Figure 4). The toe position is selected as the top of the muck pile on the bench face. These ('as-built' crest and toe) points are then digitised as a two point string and projected using the 'achieved BFA' to bench floor elevation (refer to Figure 3). On this basis, the area highlighted in blue on Figure 5 theoretically still provides catchment width (i.e. in front of the projected toe position on the floor elevation) despite the hard toe and loose spoil that may not have been removed during scaling and clean-up. At OT, the average buffer hole toe burden is $1.8 \mathrm{~m}$ so that the projected toe position should lie within this $1.8 \mathrm{~m}$ distance (assuming no buffer row/hole misfires, charging or movement issues have occurred). 


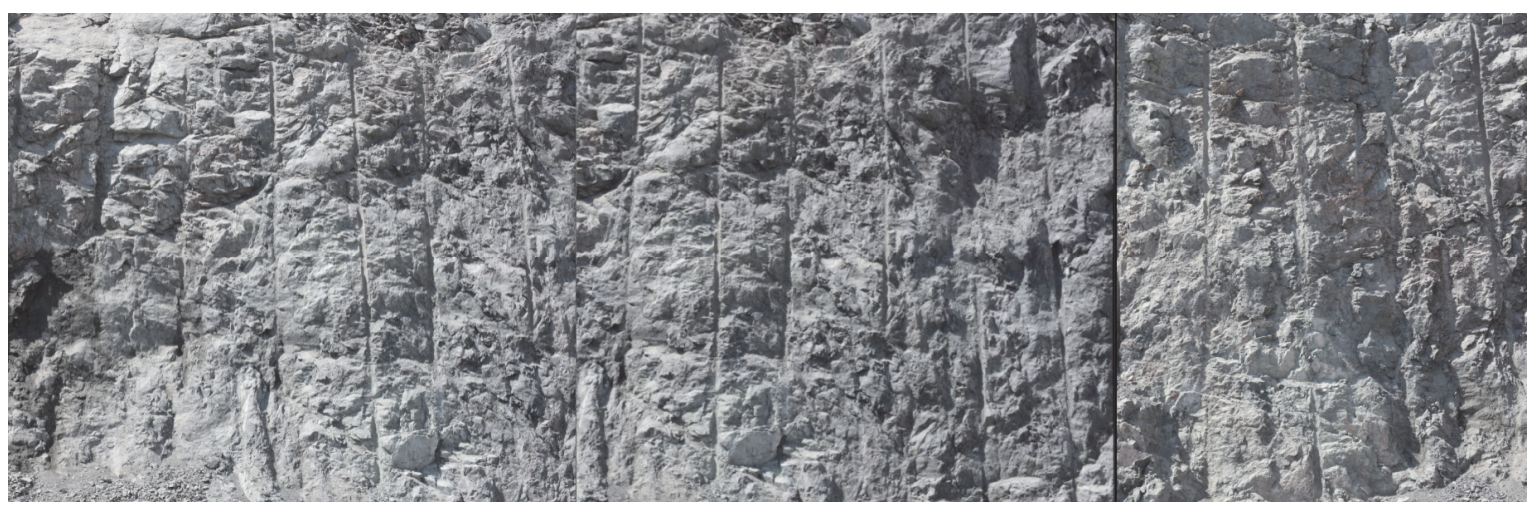

Figure 4 Half-barrels observed on the northwest wall of the Phase $4 a 930 \mathrm{mRL}$ mining bench (vertical height shown is $13 \mathrm{~m}$ )

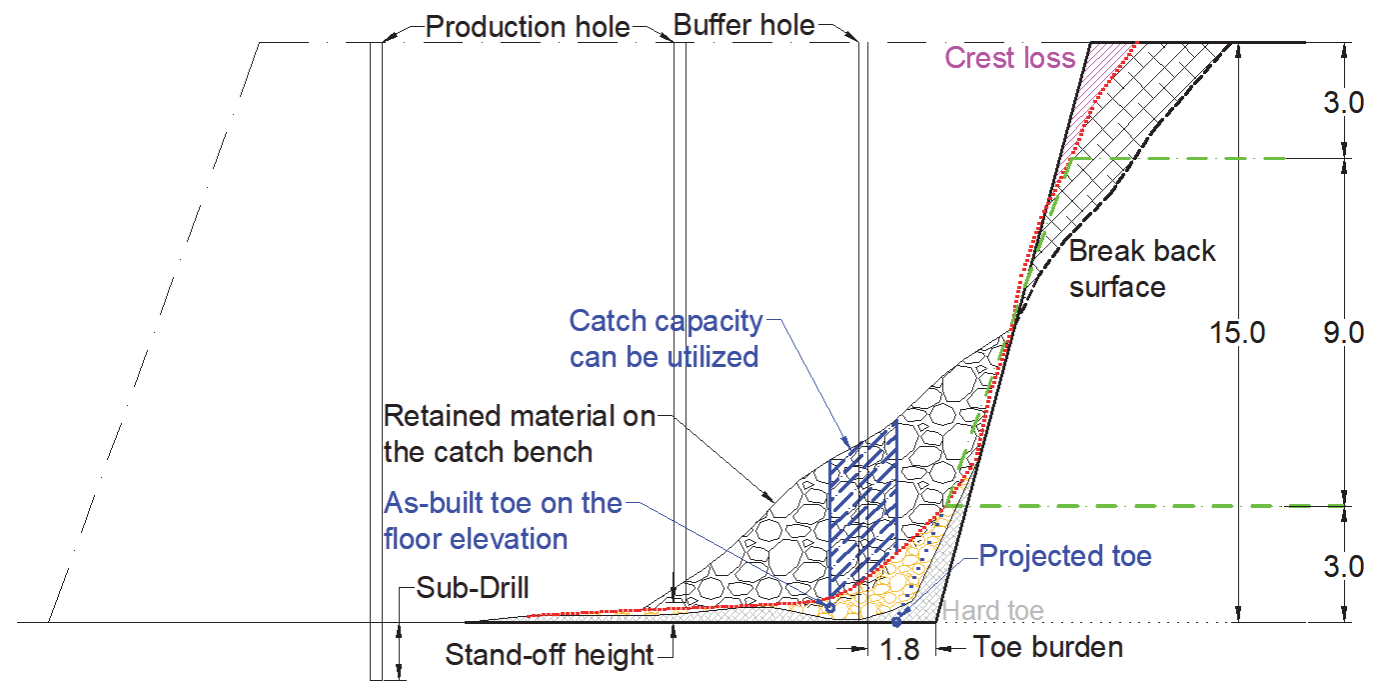

Figure 5 Typical cross-section showing catch bench capacity utilisation (where bench-scale failure has occurred following scaling and clean-up)

With regard to Figure 3, the achieved BFA is the maximum BFA that is practically achievable if crest loss resulting from blast-induced damage and over-dig of the crest is excluded from the calculation. In such cases, an improvement in drill and blast and operational practices will be necessary to increase the effective BFA to match the achieved BFA (this is where OT is seeking to minimise crest loss and toe flare). The presence of half-barrels across the wall (Figure 5 ) is a clear indication of a BFA close to/on design. Figure 3 shows the potential improvement in effective BFA is about 3 degrees and the increase in CBW is approximately $0.7 \mathrm{~m}$ when the crest loss is minimised in this manner (using the toe projection method outlined above).

Alternatively, where crest loss is due to structurally induced back-break, then effective BFA is the maximum practically achievable BFA. In this case, pit design configurations may need to be amended in some sectors in order to reflect the kinematic/structural control on practically achievable BFAs.

\subsubsection{Calculation process for proposed excavation compliance indicator method}

As mentioned, crest position is considered to be a critical element in the bench configuration (since it acts as a fulcrum controlling the BFA and CBW metrics). The upper toe (i.e. the toe on the overlying bench) is the key component of CBW. CBW is already taken into account via crest and toe position (for the $\mathrm{ECl}$ calculation). BFA is represented by crest and lower toe ('as-built' toe). Based on analysis and the relative contribution level of each element, OT propose adjustments to the ECI weighting values. See Table 3 and Figure 6 (geometric elements used to quantify design achievement). 
Table 3 OT proposed ECl weighting and values

\begin{tabular}{|c|c|c|c|c|c|}
\hline Effective BFA (20\%) & $\begin{array}{l}\text { Assigned } \\
\text { value }\end{array}$ & $\begin{array}{l}\text { Toe position } \\
\text { (projected) (30\%) }\end{array}$ & $\begin{array}{l}\text { Assigned } \\
\text { value }\end{array}$ & $\begin{array}{l}\text { Crest position } \\
\text { (crest-1) (50\%) }\end{array}$ & $\begin{array}{l}\text { Assigned } \\
\text { value }\end{array}$ \\
\hline $\mathrm{dBFA} \leq 4^{\circ}$ & 20 & $\mathrm{dTP} \leq 1 \mathrm{~m}$ & 30 & $\mathrm{dCP} \leq 1$ & 50 \\
\hline $4^{\circ}<\mathrm{dBFA} \leq 8^{\circ}$ & 15 & $1 \mathrm{~m}<\mathrm{dTP} \leq 2 \mathrm{~m}$ & 20 & $\begin{array}{l}1 \mathrm{~m}<\mathrm{dCP} \leq \\
2 \mathrm{~m}\end{array}$ & 35 \\
\hline $8^{\circ}<\mathrm{dBFA} \leq 12^{\circ}$ & 5 & $2 \mathrm{~m}<\mathrm{dTP} \leq 3 \mathrm{~m}$ & 10 & $2<\mathrm{dCP} \leq 3 \mathrm{~m}$ & 15 \\
\hline $12^{\circ}<\mathrm{dBFA}$ & 0 & $3 \mathrm{~m}<\mathrm{dTP}$ & 0 & $3<\mathrm{dCP}$ & 0 \\
\hline
\end{tabular}

Figure 6 Components of bench configuration

BFA is calculated between the as-built crest- 1 and lower as-built toe position according to the equation:

$$
B F A=\cos ^{-1} \frac{\sqrt{\left(E_{\text {crest }}-E_{\text {toe lower }}\right)^{2}+\left(N_{\text {crest }}-N_{\text {toe }} \text { lower }\right)^{2}}}{\sqrt{\left(E_{\text {crest }}-E_{\text {toe lower }}\right)^{2}+\left(N_{\text {crest }}-N_{\text {toe lower }}\right)^{2}+\left(Z_{\text {crest }}-Z_{\text {toe lower }}\right)^{2}}}
$$

where:

$$
\begin{aligned}
& E_{\text {crest }}=\text { easting of as-built crest-1. } \\
& E_{\text {toe lower }}=\text { easting of lower as-built toe. } \\
& N_{\text {crest }}=\text { northing of as-built crest-1. } \\
& N_{\text {toe lower }}=\text { northing of lower as-built toe. } \\
& Z_{\text {crest }}=\text { northing of as-built crest-1. } \\
& Z_{\text {toe lower }}=\text { northing of lower as-built toe. }
\end{aligned}
$$

CBW is calculated between the as-built primary crest and upper projected toe position (on the overlying bench) according to the equation:

$$
C B W=\sqrt{\left(E_{\text {crest }}-E_{\text {toe upper }}\right)^{2}+\left(N_{\text {crest }}-N_{\text {toe upper }}\right)^{2}+\left(Z_{\text {crest }}-Z_{\text {toe upper }}\right)^{2}}
$$

where:

$$
\begin{aligned}
& E_{\text {crest }}=\text { easting of as-built crest-1. } \\
& E_{\text {toe lower }}=\text { easting of upper projected toe. }
\end{aligned}
$$




$$
\begin{aligned}
& N_{\text {crest }}=\text { northing of as-built crest- } 1 . \\
& N_{\text {toe lower }}=\text { northing of upper projected toe. } \\
& Z_{\text {crest }}=\text { northing of as-built crest- } 1 . \\
& Z_{\text {toe lower }}=\text { northing of upper projected toe. }
\end{aligned}
$$

The variance between the design $\mathrm{BFA} / \mathrm{CBW}$ and actual $\mathrm{BFA} / \mathrm{CBW}$ is calculated according to the equations:

$$
\begin{aligned}
& B F A_{\text {variance }}=B F A_{\text {design }}-B F A_{\text {actual }} \\
& C B W_{\text {variance }}=C B W_{\text {design }}-C B W_{\text {actual }}
\end{aligned}
$$

The variance between design TOE/CREST and actual TOE/CREST positions are calculated according to the following equation:

$$
T O E_{\text {variance }}=\sqrt{\left(E_{\text {actual }}-E_{\text {design }}\right)^{2}+\left(N_{\text {actual }}-N_{\text {design }}\right)^{2}}
$$

where:

$$
\begin{aligned}
& E_{\text {actual }}=\text { easting of upper projected toe. } \\
& E_{\text {design }}=\text { easting of upper design toe. } \\
& N_{\text {actual }}=\text { northing of upper projected toe. } \\
& N_{\text {design }}=\text { northing of upper design toe. }
\end{aligned}
$$

$$
C R E S T_{\text {variance }}=\sqrt{\left(E_{\text {actual }}-E_{\text {design }}\right)^{2}+\left(N_{\text {actual }}-N_{\text {design }}\right)^{2}}
$$

where:

$$
\begin{aligned}
& E_{\text {actual }}=\text { easting of as-built crest-1. } \\
& E_{\text {design }}=\text { easting of design crest. } \\
& N_{\text {actual }}=\text { northing of as-built crest-1. } \\
& N_{\text {design }}=\text { northing of design crest. }
\end{aligned}
$$

As shown in Table 4, the overall ECI score comprises weighted scores for BFA, crest and toe. OT have revised crest (as-built crest-1) and toe (projected toe) tolerances to better reflect the importance of CBW (which is calculated from the as-built crest-1 position and the upper toe). See Figure 6.

Table $4 \quad \mathrm{ECl}$ value matrix

\begin{tabular}{llllllll}
\hline \multicolumn{2}{l}{ Effective bench face angle } & $\begin{array}{l}\text { Crest/toe } \\
\text { position }\end{array}$ & $\begin{array}{l}\text { Crest } \\
\text { tolerance }\end{array}$ & $\begin{array}{l}\mathrm{dCP} \leq \\
\mathbf{1 ~ m}\end{array}$ & $\begin{array}{l}\mathbf{1} \mathbf{m}<\mathrm{dCP} \\
\mathbf{2} \mathbf{m}\end{array}$ & $\begin{array}{l}\mathbf{2}<\mathrm{dCP} \\
\mathbf{3} \mathbf{m}\end{array}$ & $\begin{array}{l}\mathbf{3} \mathbf{m}< \\
\mathbf{d C P}\end{array}$ \\
\hline Tolerance & $\begin{array}{l}\text { Assigned } \\
\text { value }\end{array}$ & Toe tolerance & $\begin{array}{l}\text { Assigned } \\
\text { value }\end{array}$ & 50 & 35 & 15 & 0 \\
$\mathrm{dBFA} \leq 4^{\circ}$ & 20 & $\mathrm{dTP} \leq 1 \mathrm{~m}$ & 30 & 100 & 70 & 45 & 30 \\
$\begin{array}{l}4^{\circ}<\mathrm{dBFA} \leq 8^{\circ} \\
8^{\circ}<\mathrm{dBFA} \leq\end{array}$ & 15 & $1 \mathrm{~m}<\mathrm{dTP} \leq 2 \mathrm{~m}$ & 20 & 75 & 55 & 35 & 20 \\
$12^{\circ}$ & 5 & $2 \mathrm{~m}<\mathrm{dTP} \leq 3 \mathrm{~m}$ & 10 & 60 & 45 & 25 & 10 \\
$12^{\circ}<\mathrm{dBFA}$ & 0 & $3 \mathrm{~m}<\mathrm{dTP}$ & 0 & 50 & 35 & 15 & 0 \\
\hline
\end{tabular}

To quantify the variation between design and actual (scanned survey data), the geometrical elements of each are first assessed/compared using Mintec MineSight CAD tools (Hexagon AB 2019). The software is used to 
create cross-sections every $5 \mathrm{~m}$ orthogonal to the design crest line, thereby creating a point that intersects the as-built crest and toe lines on each vertical cross-section (see example shown in Figure 7). This process is used to systematically extract upper toe, crest and lower toe positions, as well as assign attributes in order to group the points according to geometrical element type. The various geometrical data is then exported to a Microsoft (MS) Excel template to perform further analytical work. A work flow diagram outlining the manipulation process is shown in Figure 8.

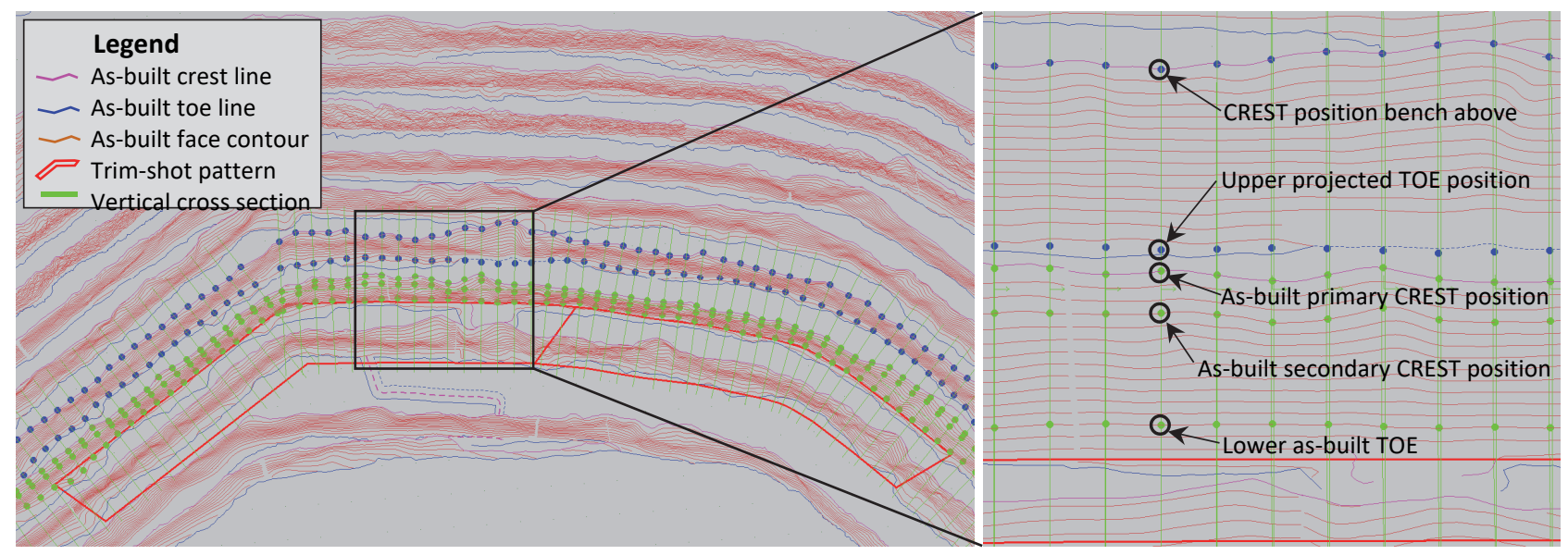

Figure 7 MineSight interface and derivation of as-built geometric elements for further analysis

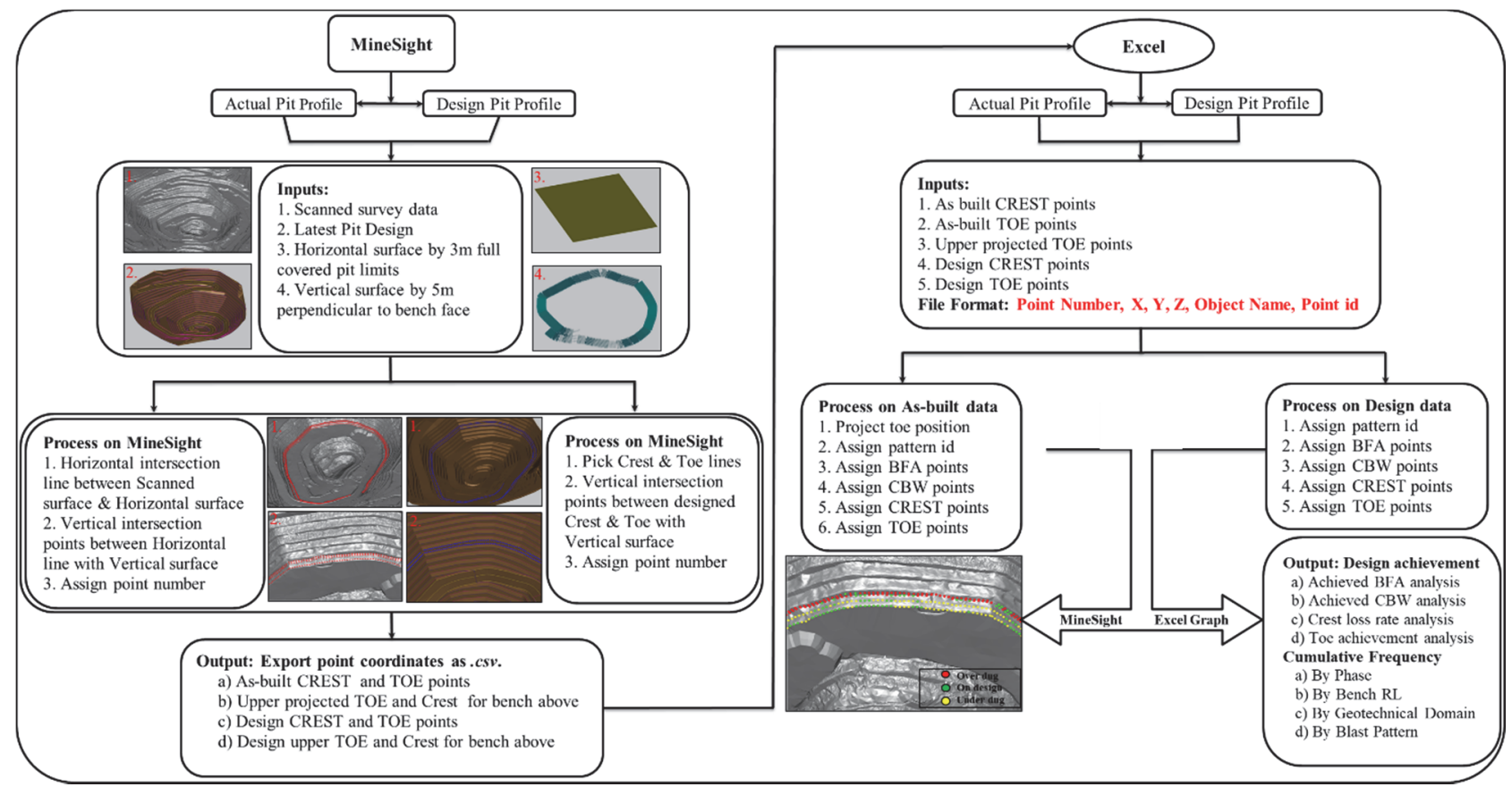

Figure 8 Oyu Tolgoi excavation compliance indicator workflow chart

\section{Excavation compliance indicator data processing and analysis at Oyu Tolgoi}

$\mathrm{ECl}$ calculations and associated data using the Williams et al. (2009) bench design achievement evaluation method were originally stored in a series of individual MS Excel sheets held in separate folders (for each phase, bench and trim shot pattern id).

OT has subsequently developed a macro-enabled MS Excel data platform/template, which has been applied from all mining benches from $975, \mathrm{mRL}$ to the current mining elevation at $900 \mathrm{mRL}$ (i.e. imports all data into 
a single template). This platform provides the following advantages and capabilities over the previous data processing and analytical method:

- A fully automated data template with improved work flow (the month-end reconciliation process is now three times faster).

- ECl data was previously assessed on individual sheets, so was fragmented and restricted the quality of data analysis that could be undertaken. Historical data has now been consolidated into a single database which enables more comprehensive data interrogation. Instead of multiple individual assessment sheets, data has been consolidated into a single database containing five mining benches and comprising a total of 61 controlled (trim shot) blasts and 1,916 design reconciliation sections. The OT geotechnical team are currently working to upload all historical data into the new MS Excel platform.

- Functionality has been added to provide enhanced graphing and data displays, facilitating improved interrogation of slope metrics. Additionally, the sheet has been developed to provide functionality for interactive analysis of a range of variables (i.e. phases, mining benches, blast patterns id, geo-domains and slope aspect).

- Data output also enables design reconciliation based on achieved inter-ramp angle (by slope aspect and geo-domain). The platform allows geotechnical domain boundaries to be flagged, so that ECI scores per geo-domain can be interrogated.

- Finally, the system includes functionality enhancements to enable calculation of statistical distribution of design achievement, automated cumulative frequency analysis, and improved visual display of $\mathrm{ECl}$ conformance.

Figure 9 illustrates the benches that have been imported into the OT ECI template to date. The OT geotechnical team will upload all other historical data in due course.

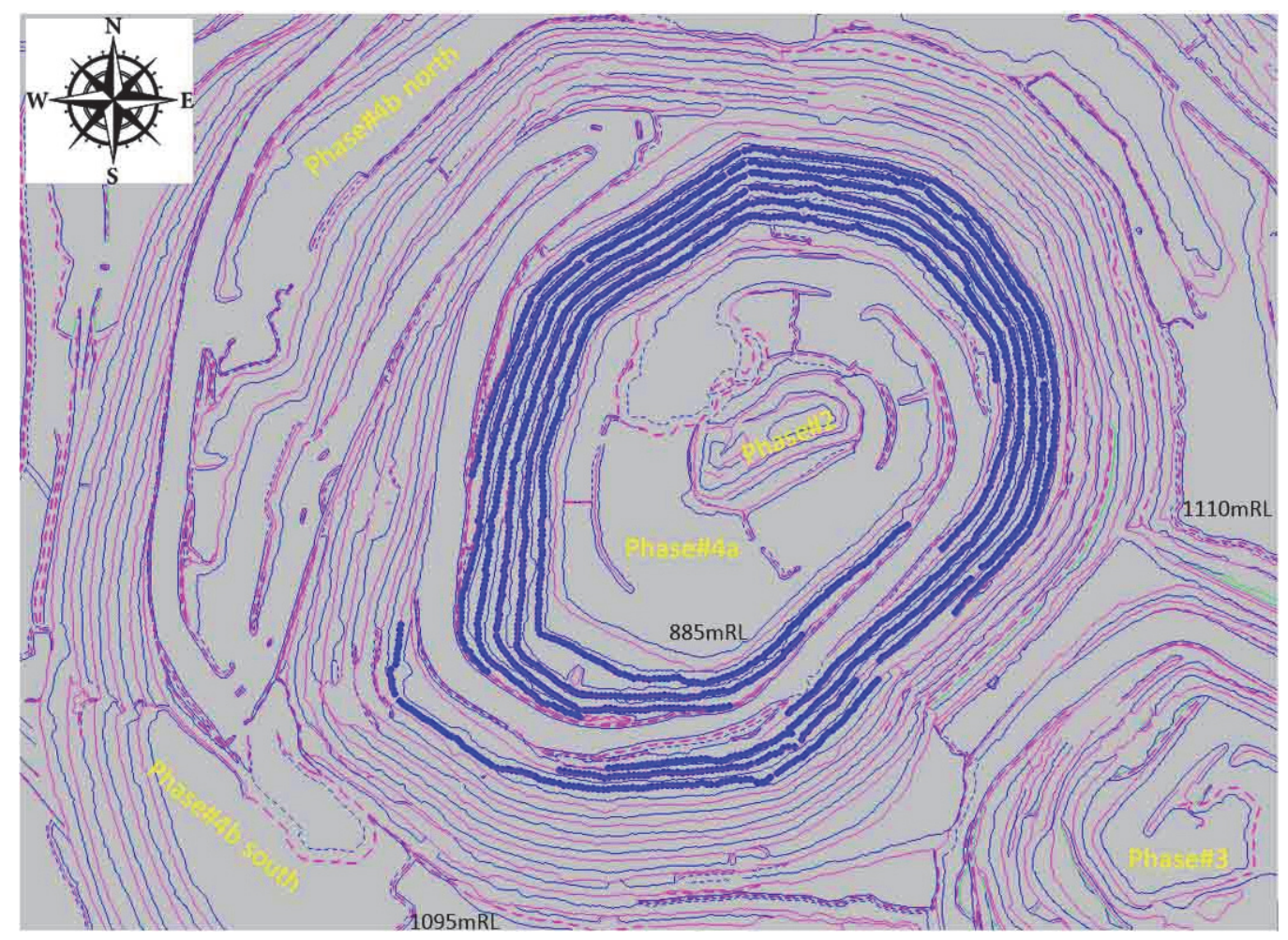

Figure 9 Plan of the lower (975 to $900 \mathrm{mRL}$ ) Phase 4a pit using as-built survey contours (with crest position calculation points superimposed in blue) 
Figures 10 to 15 illustrate some of the output and functionality that is automatically generated from the data analysis process (this enables much improved data interrogation and interpretation).

The graphs show calculated $\mathrm{ECl}$ values generated by using the same dataset based on the existing $\mathrm{ECl}$ process versus those generated using the refined OT ECI metrics, weightings and tolerances (as outlined in Section 2). In this example, there is a significant change on BFAs considered to be on design (i.e. $7.2 \%$ on design within the original $3^{\circ}$ tolerance compared to $16.6 \%$ on design using the proposed OT $4^{\circ}$ tolerance). Minor improvements are delivered on CBW and toe achievement metrics.
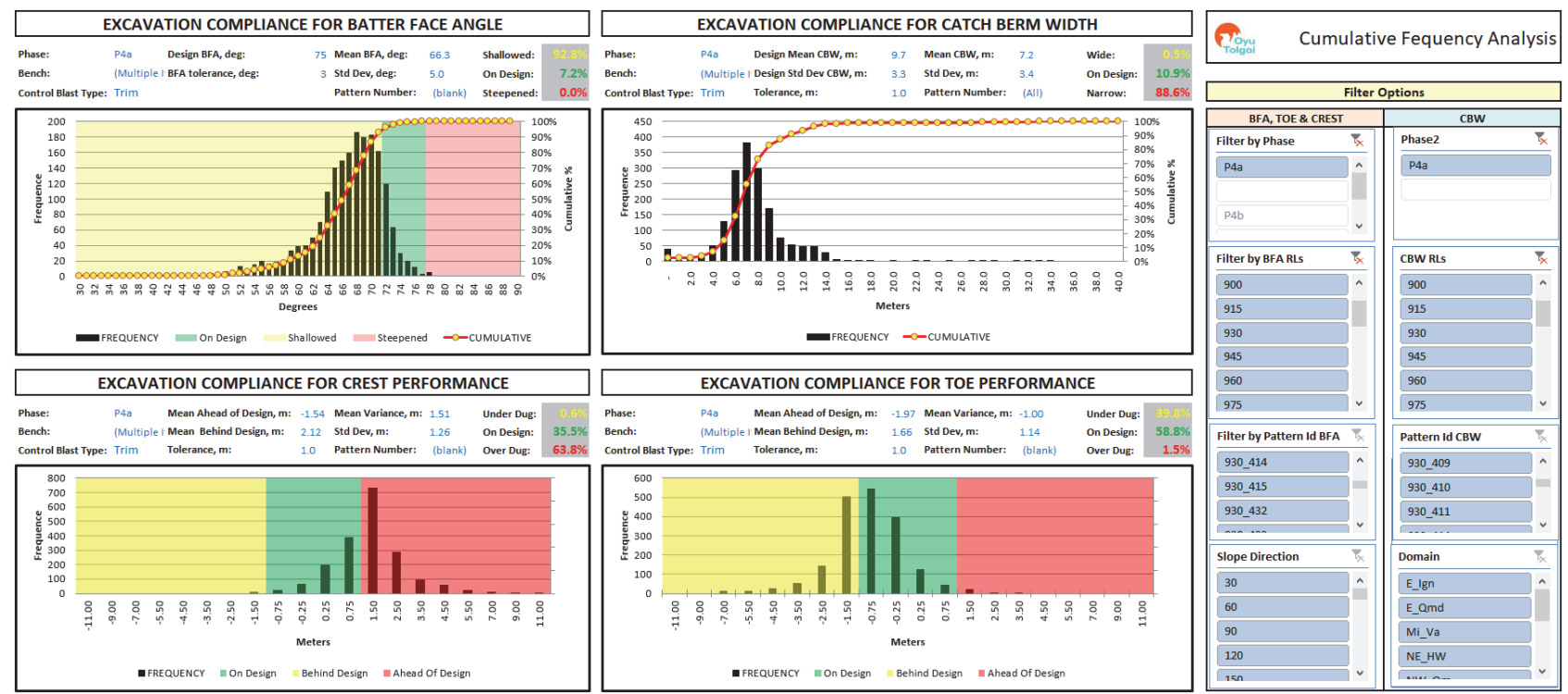

Figure 10 Statistical analysis using the previous excavation compliance indicator method
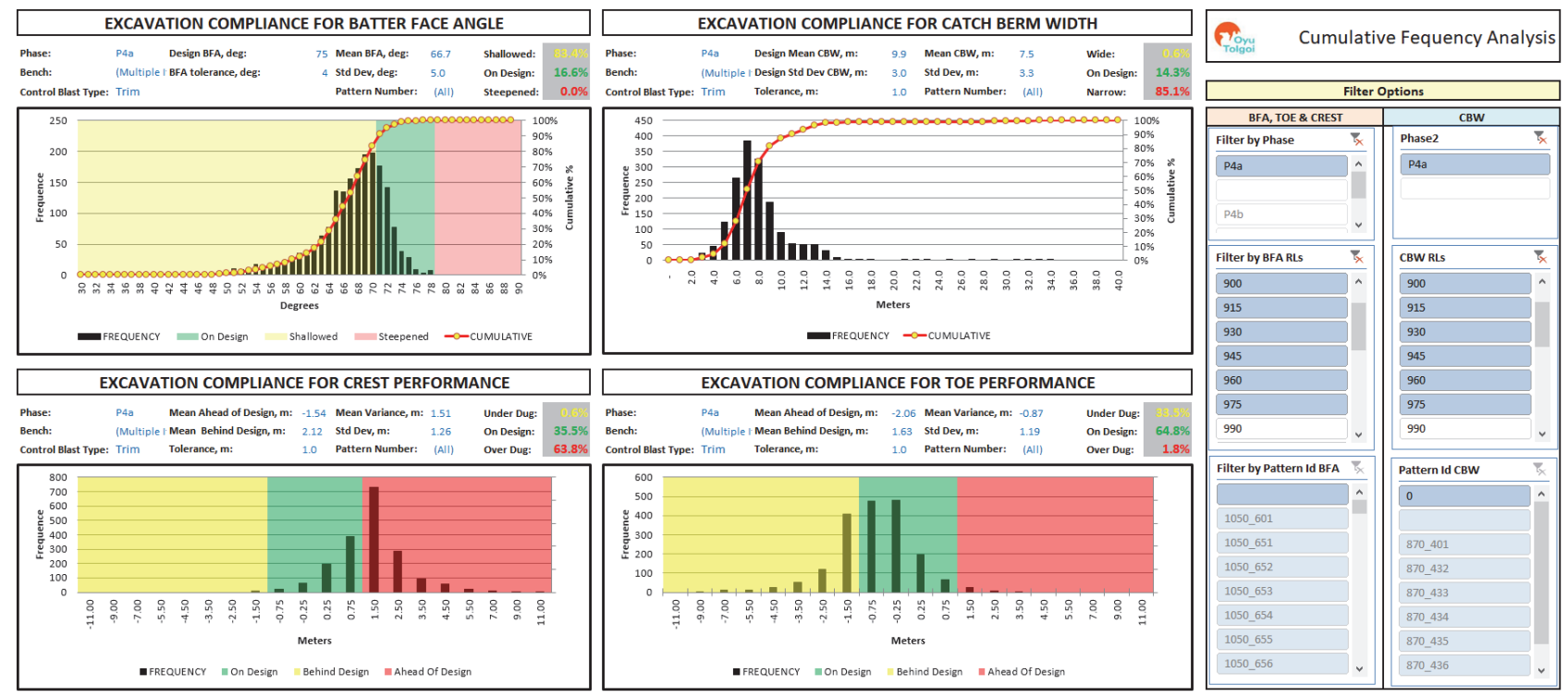

Figure 11 Statistical analysis using the revised excavation compliance indicator method 


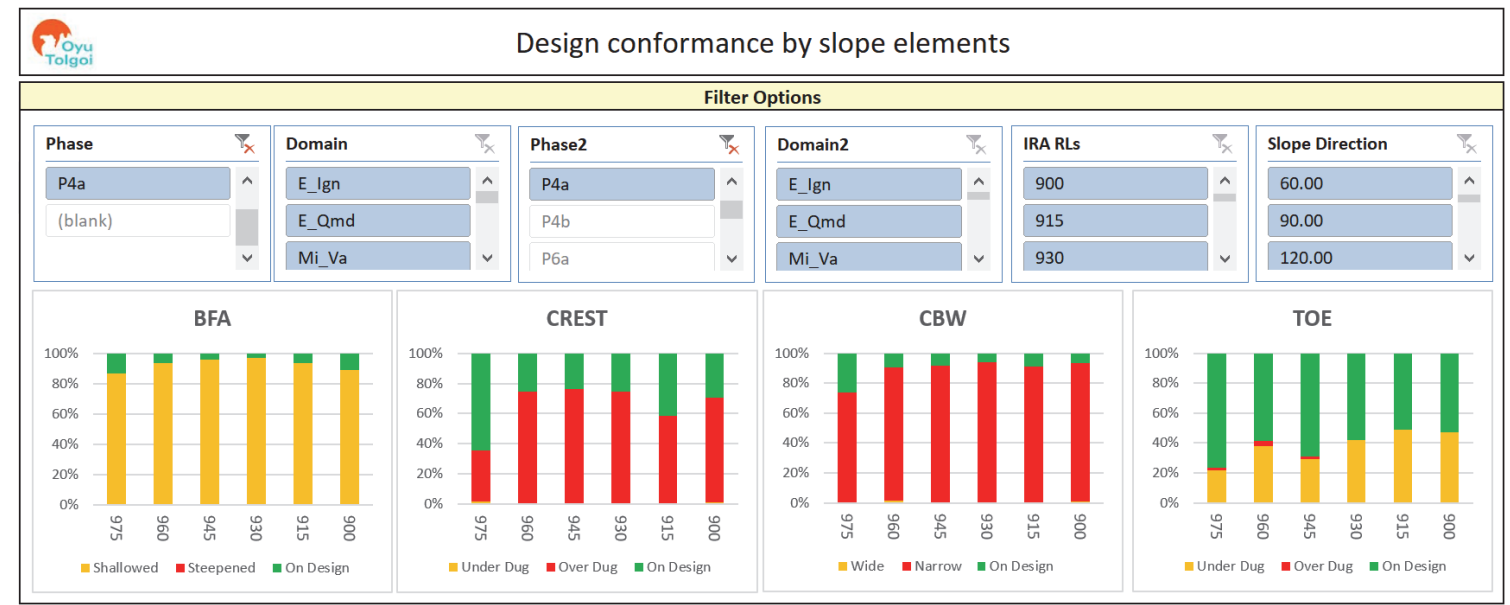

Figure 12 Design conformance of slope elements using the previous excavation compliance indicator method

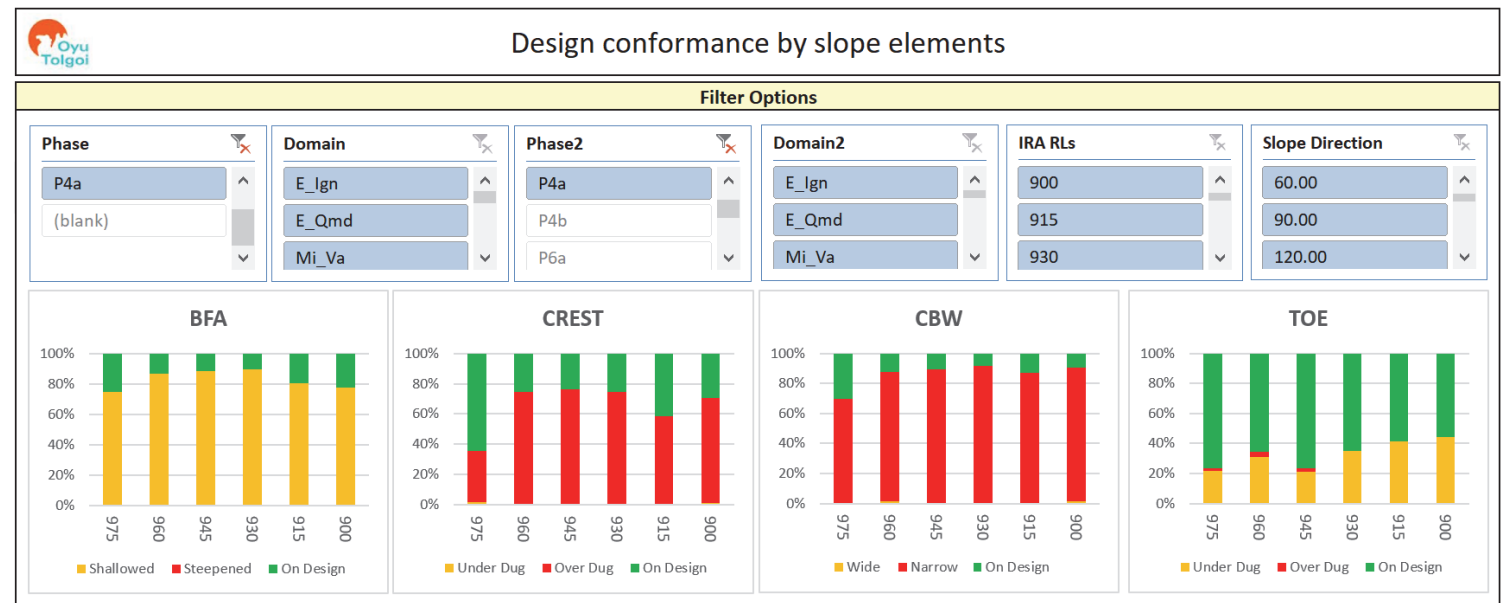

Figure 13 Design conformance by slope elements using the revised excavation compliance indicator method

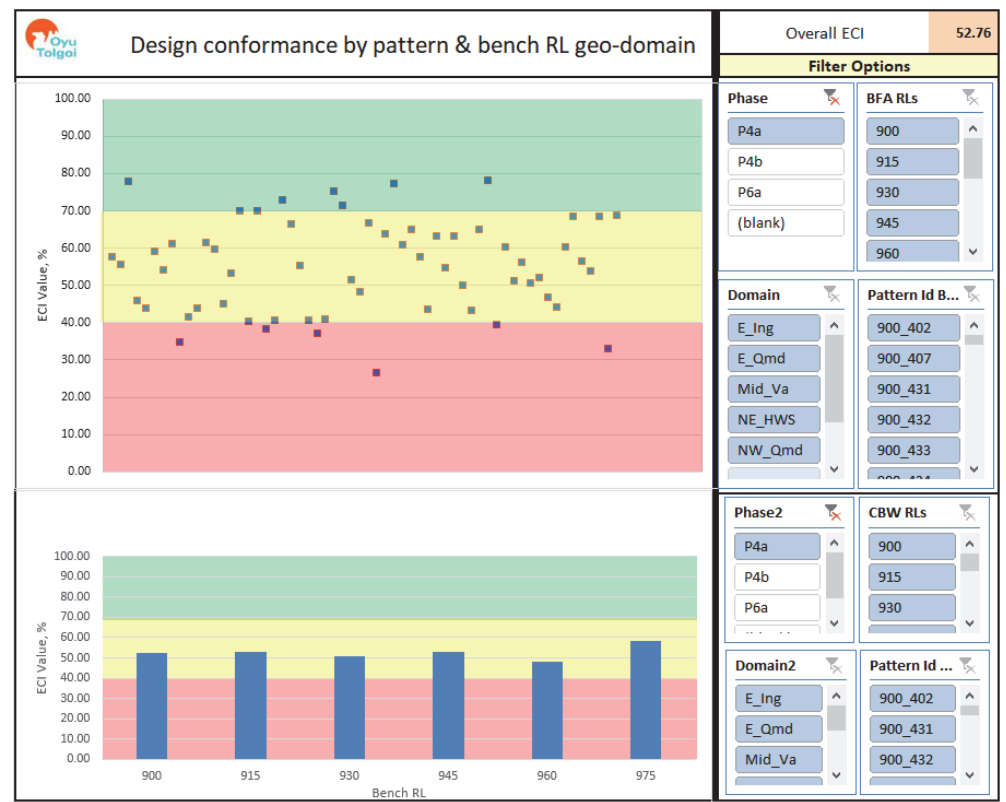

Figure 14 Design conformance by bench elevation blast pattern ID and geo-domain (previous excavation compliance indicator method) 


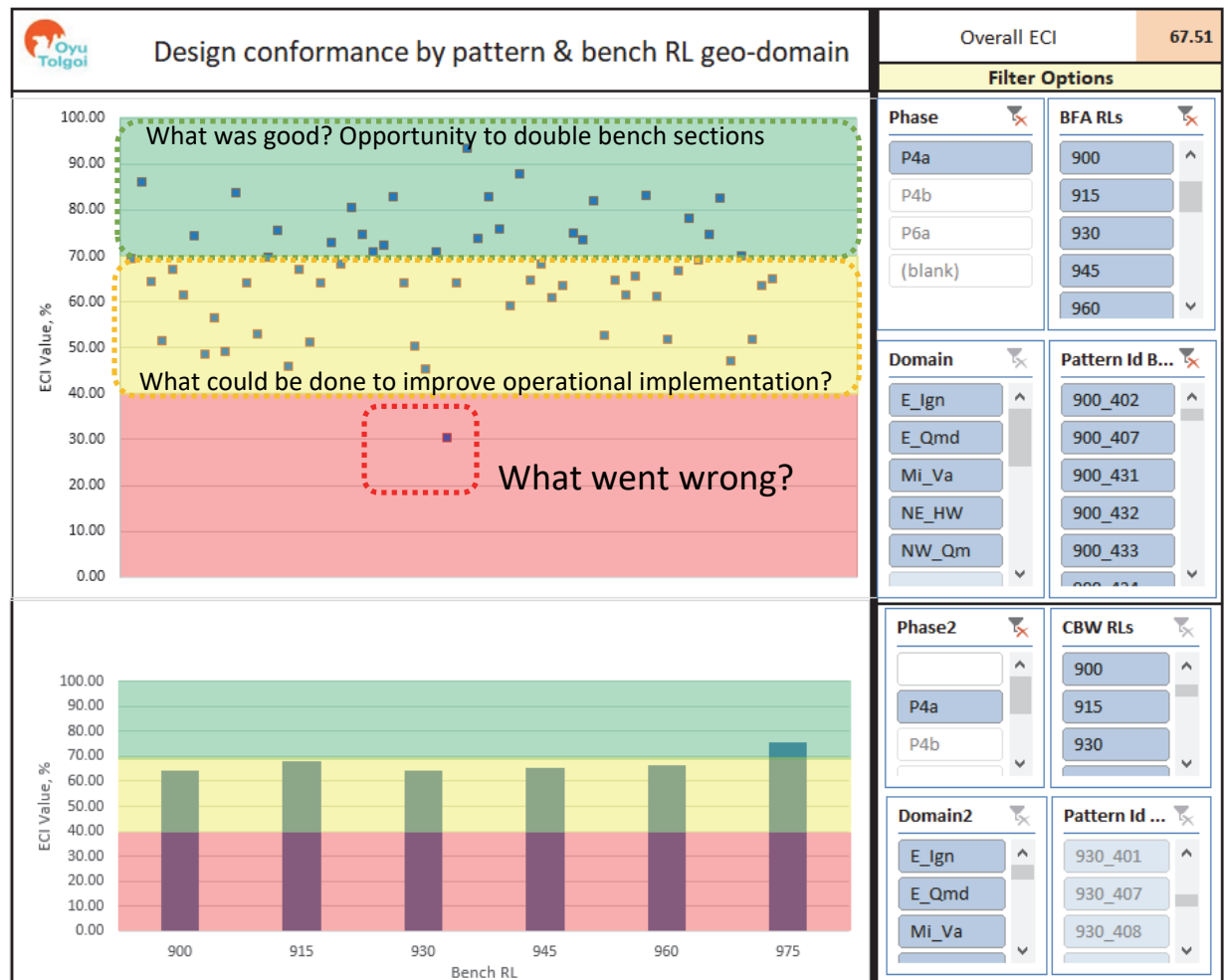

Figure 15 Design conformance by bench elevation blast pattern ID and geo-domain (revised excavation compliance indicator method)

As shown in Figures 13 to 15 , the overall $\mathrm{ECl}$ value can be populated into a tripartite 'traffic light' classification, namely:

1. $\geq 70 \%$ designated as 'good'.

2. Between $70 \%$ and $40 \%$ designated as 'moderate'.

3. $\leq 40 \%$ designated as 'poor'.

The calculated final $\mathrm{ECl}$ value can be used for design implementation, as described in Table 5.

Table 5 Excavation compliance indicator value categories and descriptions applied at Oyu Tolgoi

\begin{tabular}{|c|c|c|}
\hline Description & ECl value & Comments \\
\hline \multirow[t]{2}{*}{ Good } & $\geq 70$ & $\begin{array}{l}>85 \% \text { further investigation and analysis are required to assess any potential } \\
\text { opportunities to modify the slope geometry. }\end{array}$ \\
\hline & & $\begin{array}{l}\text { Between } 70 \% \text { and } 85 \% \text { further investigation and analysis are required to } \\
\text { assess any potential double bench opportunities. }\end{array}$ \\
\hline \multirow[t]{2}{*}{ Moderate } & $>40$ & $\begin{array}{l}\text { Between } 55 \% \text { and } 70 \% \text { is a generally acceptable condition (e.g. if kinematics } \\
\text { permit, seek improvement by adopting similar operational practices to those } \\
\text { employed in the 'good' category). }\end{array}$ \\
\hline & & Between $40 \%$ and $55 \%$ is an area requiring attention (improvement required). \\
\hline \multirow[t]{2}{*}{ Poor } & $\leq 40$ & $\begin{array}{l}\text { Between } 30 \% \text { and } 40 \% \text { is an area requiring specific attention (detailed } \\
\text { investigation to understand the root cause of the poor } \mathrm{ECl} \text { achievement). } \\
\text { A design change may be required. }\end{array}$ \\
\hline & & $\begin{array}{l}<30 \% \text { consider design change to shallower BFA or wider CBW based on } \\
\text { (assessed) contributing factors. }\end{array}$ \\
\hline
\end{tabular}




\section{Conclusion}

This paper outlines how the OT open pit geotechnical team implements ECl. Specifically, the paper presents a description of the OT ECI workflow and the areas in which OT has been seeking to refine $\mathrm{ECI}$ reconciliation practices and work efficiencies. Improvements include the establishment of a macro-driven MS Excel spreadsheet, which acts as a consolidated database of historical ECI results. The sheet has functionality to undertake interactive analysis of different variables, including statistical distribution of design achievement; automated cumulative frequency analysis; and visual display of $\mathrm{ECl}$ conformance (by geo-domain). In combination, the developments have resulted in significant workflow improvements and analytical capability.

Every deposit has its own litho-structural characteristics and mining practices that could directly or indirectly affect design achievement. Design achievement tolerances should be applied to the BFA, crest and toe elements based on equipment size and operational practices; i.e. $\mathrm{ECl}$ tolerances and weightings should be deposit-specific. In this regard, the $\mathrm{ECl}$ system and methodology has been developed to be specific for the circumstances at OT. The objective is not simply to calculate an $\mathrm{ECl}$ value, but to drive process improvement and design implementation in the pit. Not only has this got a commercial imperative (in terms of maximising ore recovery), but also in managing the safety risks arising from poor slope design conformance.

Crest and toe positions are critical elements in the bench design configuration since both BFA and CBW are fully dependent on these components (i.e. act as loci for quantifying the variability between the design and 'as-built' bench slope). Quantifying design achievement using only BFA and CBW might lead to misinterpretation due to the fact that line angles and lengths may be ahead or behind the design slope.

\section{Acknowledgement}

The author thanks Chinbat Shijirbaatar, Michael Campbell, Sugarsuren Ganbaatar, and other members of the Oyu Tolgoi geotechnical team.

\section{References}

Hexagon AB 2019, MineSight 3D, computer software, Hexagon AB, Stockholm, https://hexagonmining.com/products/all-products/ minesight-3d

Seery, J \& Lapwood, J 2007, 'Use of an excavation compliance indicator to assess conformance to slope design', in Y Potvin (ed.), Proceedings of the 2007 International Symposium on Rock Slope Stability in Open Pit Mining and Civil Engineering, Australian Centre for Geomechanics, Perth, pp. 431-437.

Williams, P, Floyd, J, Chitombo, G \& Maton, T 2009, 'Design implementation', in J Read \& P Stacey (eds), Guidelines for Open Pit Slope Design, CSIRO Publishing, Collingwood, pp. 265-326 